\title{
Openness and scientists' everyday research processes
}

Exploring the factors related with scientists' willingness to incorporating external knowledge

\section{CHEPS WORKING PAPER 04/2015}

Julia Olmos-Peñuela. Dep. de Direcció d'Empreses 'Juan Jose Renau Piqueras' (Universitat de València) julia.olmos@uv.es

Paul Benneworth. CHEPS (University of Twente) p.benneworth@utwente.nl

Elena Castro-Martínez. INGENIO (CSIC-Universitat Politècnica de València) ecastrom@upvnet.upv.es

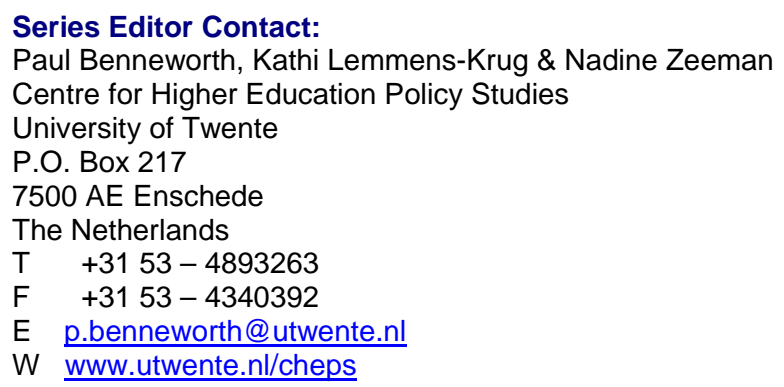




\section{Table of Contents}

Abstract

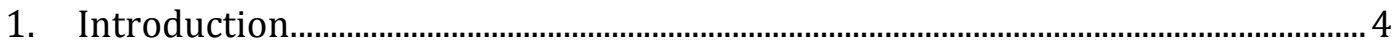

2. From 'knowledge suitable for terminal transfers' towards 'knowledge cognate

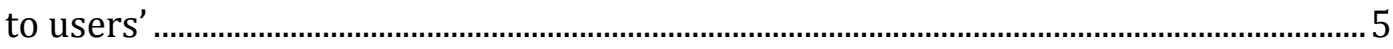

3. Open research behaviour as an antecedent of usable knowledge .............................. 7

4. Characteristics that might be associated with openness ...........................................

4.1 Professional characteristics associated with openness ................................... 10

4.2 Personal characteristics associated with openness ............................................. 13

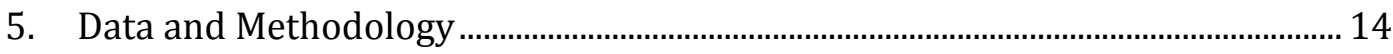

5.1. Data collection and population ...................................................................... 14

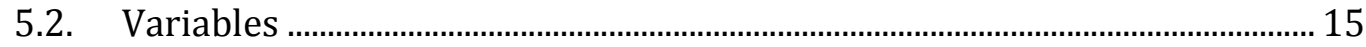

5.3. Analysis and test considerations ......................................................................... 19

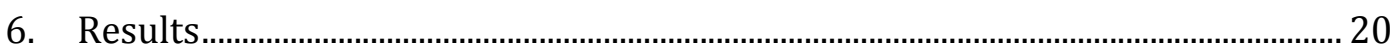

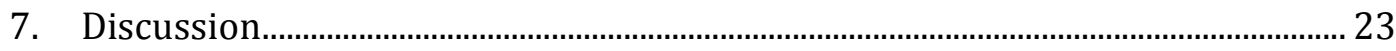

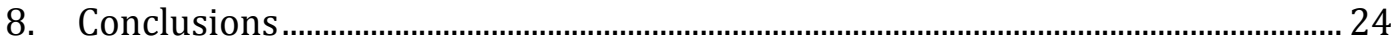

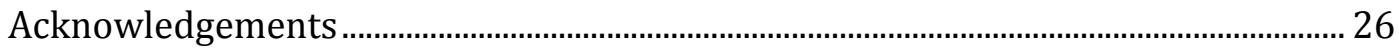

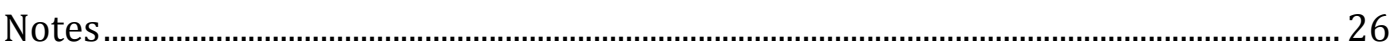

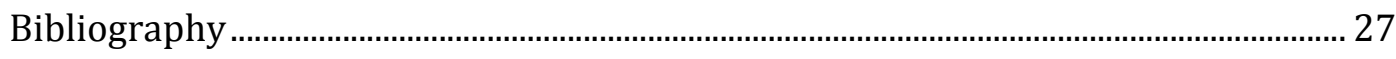




\section{Abstract}

Science policy increasingly focuses on maximising societal benefits from science and technology investments, but often reduces those benefits to activities involving codifying and selling knowledge, thereby idealising best practice academic behaviours around entrepreneurial superstars. This paper argues that societal value depends on knowledge being used, making knowledge's eventual exploitation partly dependent upon on whether other users - societal or scientific - can use that knowledge, i.e. on how far new knowledge is cognate with users' existing knowledge. When scientists incorporate user knowledge in their research processes, what we call 'open research behaviours', their knowledge may be more usable. We develop a set of hypotheses concerning whether researchers' personal and professional characteristics are associated with open research behaviour, finding evidence suggesting whilst personal characteristics are not associated with open research behaviours; researchers that experience professional signals validating open research behaviours are more likely to demonstrate open research behaviour.

Key words: science and innovation policy, technology transfer, knowledge exchange, research processes, mode 2 research practices, knowledge production.

JEL codes: I23 - Higher Education Research Institutions; 031 - Innovation and Invention: Processes and Incentives; 033 - Technological Change: Choices and Consequences; Diffusion Processes; JEL: 038 - Government Policy (Technological Change, R\&D); 032 Management of Technological Innovation and R\&D 


\section{Introduction}

There has been increasing interest in recent years in the public value of science, the contributions that investing in science generates beyond the academic realm, in terms of creating new social, economic, cultural and democratic capacities (e.g. Adviesraad-voor-Wetenschaps 2007). The justification for investment in universities has always partly been in terms of their social contributions (e.g. Rüegg 1992; Ernste 2007), and Vannevar Bush's (1945) The Endless Frontier articulated this relationship explicitly: investing in university science research as a direct means of stimulating wider technological advance. In more recent decades, a closer relationship has been claimed by some between university research activities and economic development ( $c f$. Berman 2011), stimulating great interest among academic researchers and policy makers to measure the societal contribution of research. The archetype has emerged of the entrepreneurial academic who undertakes research and then arranges for it to be exploited and transferred in ways that ultimately lead to economic development.

There is an emerging body of literature that is starting to try to understand what motivates these heroic academics under these circumstances to engage with outside partners and ensure that their research is effectively used (e.g. D'Este and Perkmann 2011; Lam 2011). There is evidence that entrepreneurial performance can be correlated with improved research performance, and that star entrepreneurial scientists (in terms of spin-offs, patents and licensing) are also high performing scientists in terms of academic productivity and excellence, and likewise that strong research environments are highly stimulating for entrepreneurial activities (Van Looy et al. 2004; Gulbrandsen and Smeby 2005; O'Shea et al. 2005; Lowe and Gonzalez-Brambila 2007). We contend that highly positive narratives overlook the negative consequences that engagement might have for academic independence and standing, and the risks that these negative effects might reduce the overall public value created by academic research (Slaughter and Leslie 1997; Bozeman 2012).

Analyses of these direct relationships have been criticised more generally from a variety of directions. In particular these have come from only attempting to quantify those kinds of relationships which are both directly evident and easily quantifiable (Donovan 2007). This is problematic firstly for ignoring the sometimes indirect and non-linear pathways by which scientific knowledge drives socio-economic development (Bozeman 2000; Salter and Martin 2001). Secondly, there has been a focus on a narrow and limited set of entrepreneurship mechanisms relating to formal activities directly associated with economic activity, framing academic entrepreneurship in ways that favours particular kinds of disciplines over others ( $c f$. Benneworth 2015). By focusing on a limited number of direct transactions, there is a prima facie risk of framing this view of the public value of science in ways that contains a public value failure (cf. Bozeman 2002). ${ }^{1}$ 
Therefore, in this paper we seek to get beyond these limitations by considering the public returns to science investment as an issue of returns from a system, and consider which kinds of scientist ${ }^{2}$ and scientific behaviour best contribute to maximising these returns. We wish to contribute to a growing set of scientific debates exploring what motivates academics to take particular kinds of decisions in their research activity, decisions that shape the ultimate characteristics of their findings (Bateman and Hess 2015). Our starting point here is a critique to existing approaches that assume that the best system-level returns are produced by optimising a particular kind of technology transfer transaction ${ }^{3}$. To get beyond this, we argue that optimum aggregate public returns from science emerge when research is usable by others, even where is not a readily-countable 'transaction' from a knowledge producer to a user. What therefore regulates whether research is usable is not whether there are users, but the potentiality and feasibility of it to be used by others involved in knowledge creation, whether scientific or societal.

Therefore, we argue that a science system that optimises its public value also optimises the external usability of the knowledge it produces outside the immediate scientific community which brought it forth. We use this as our starting point to the overall question of which kinds of scientists produce the most usable knowledge, defining the characteristic of 'openness' as a willingness to incorporate knowledge from partners outside the immediate academic setting into the research process as an indication that this knowledge will be more usable ( $c f$. Olmos-Peñuela et al. 2014b). We then identify which kinds of characteristics are associated with higher levels of openness to reflect on what kind of researchers are best contributing to optimising the public value of the science system beyond simplistic narratives of 'superstar entrepreneurial academics creating pharmaceutical spin-off companies'.

\section{From 'knowledge suitable for terminal transfers' towards 'knowledge cognate to users'}

We argue that the problem is the oversimplification of how valorisation takes place and, in particular, the assumption that the only knowledge that has social value is knowledge which has already been used by societal agents. That assumption can be regarded as a specific example of a more linear model problem within science, technology and innovation studies. Although there is a widespread recognition that the relationship between science and society is not linear, assuming that science is firstly produced and only then encounters users is common amongst policy-makers (and also among science policy scholars communicating with policymakers) as a way of creating clarity and certainty in an extremely complex policy environment. Naïve (what Balconi et al. 2010) call the 'straw man') linear models recur in unexpected places in science studies embedded in common-sense assumptions and framings of how scientific systems and processes operate. 
Nowhere is this problem more evident than in conceptions of valorisation, of investments in academic research creating value for society - a formulation that carries with it a sense of a linear model -, of funding invested in one domain, 'science', to produce benefits in a downstream domain, 'society' ( $c f$. Benneworth 2015). This reduces a systemic relationship between domains in which knowledge is produced interactively and, from that shared knowledge pool, some of that is used in 'society' to a set of one-to-one transactions between knowledge producers and knowledge users. We contend that there is too much emphasis for the 'terminal transfer' in which a user interacts productively to acquire a piece of knowledge (Spaapen and van Drooge 2011) and embed it in the socio-economic domain. Following Spaapen and van Drooge (2011), that terminal transfer may correspond to a formal transaction, such as a patent license or spin-off company, or to an informal interaction, such as an exhibition or trade show, or an indirect acquisition such as by an article in the popular press.

This critically overlooks the various foundation pieces of knowledge embedded in the scientific knowledge that is acquired through that terminal transfer. The business of academic knowledge production can be understood as taking place within scientific communities (Latour and Woolgar 1979; Becher and Trowler 2001). Academic knowledge production is additive, with current research building on or challenging the existing knowledge base, often mediated through institutions such as journals which serve to codify and embody the academic state-of-the-art.

That knowledge addition process involves knowledge being transferred between an originator and an acquirer. Effective transfer process requires that user and generator have a common set of understandings, definitions, concepts and assumptions which form the basis for allowing particular items of knowledge to be transferred by setting the boundaries and the contexts for meanings (Gertner et al. 2011). Knowledge exchange between actors requires therefore that they have a knowledge cognateness, that they are sufficiently proximate to one another in terms of their understandings to have a meaningful exchange - particularly where that exchange is not direct, for instance mediated at a distance through texts (Boschma 2005; Fromhold-Eisebith et al. 2014).

We contend that one mechanism by which knowledge is used and creates value for society is the one that contributes additively to knowledge that reaches final users via terminal transfers. The corollary of this is that in order to maximise the returns on investment from the science system, it is necessary not only to ensure that there is a good level of these terminal knowledge transfers, but also that there is a good flow of antecedent knowledge that contributes effectively to terminal knowledge transfer. We consequently contend that this antecedent research also leads to the creation of public value 4 . Hence, we argue that what makes research 'usable' is therefore the characteristic that it can easily be absorbed (and used) by others, whether scientific or societal users. But of course not all scientific 
knowledge will ultimately embedded in societally-used knowledge, and we are keen to avoid an output fallacy in which we argue that producing more knowledge leads to more impact.

This raises the question of what kinds of knowledge are more capable of flowing in pre-terminal (or antecedent) transfers - i.e. those that ultimately end up leading to societal value. It is this question that this paper seeks to address, to expand the debate about 'useful knowledge' beyond trying to identify what kinds of knowledge are more easily exploited by users, to what kinds of science system can therefore deliver the best contributions to their host societies. To address that issue, we argue that the knowledge most likely to become incorporated into terminal knowledge transfer is that which builds on antecedent knowledge that is cognate with users, and hence most easily acquired by them.

\section{Open research behaviour as an antecedent of usable knowledge}

We argue on that basis that the knowledge that is most likely to flow into terminal transfers is that knowledge which has some cognateness with the interests and needs of users. We argue that knowledge is cognate with user knowledge when it is most actively produced in communities where users are active agents in knowledge production activities (Gibbons et al. 1994; Nowotny et al. 2001). Our heuristic here is a domain like chemical engineering, whose concern is intensely practical in its orientation, although not all academics are directly oriented towards working with users. There are common scientific problems that local and wider communities seek to address; that scientific problem-solving cycle is framed by these practical orientations that ensure that even abstract knowledge is oriented-constructed in such ways that allows those working directly with users to acquire and transfer it to society (Dance 2013). This does not necessarily mean that all knowledge within the community will be produced in direct interaction with users, but the aggregate effect will be to create more opportunities to overlap with user interests.

Continuing the Mode 2 (non-linear) line of argumentation, we likewise contend that it is those scientists who create knowledge drawing on what we regard as external knowledge that will in turn generate new knowledge that is of potential greater usability for users (Gibbons et al. 1994; Nowotny et al. 2001), because of this quality of cognateness (i.e. knowledge constructed on external knowledge is more cognate with these external knowledge fields). Here we define external fields as those that have different framing principles to the scientist's core academic community, whether in other academic disciplines, or with societal users: in each case acquiring that knowledge is not an intra-paradigmatic task and requires this property of cognateness. Drawing and building upon external knowledge means that the research is already oriented towards areas of potential 
user interest - even when it is undertaken in a very fundamental way and it is not necessarily immediately digestible for users.

We therefore argue that there is a link between the extent to which academic researchers draw on users' knowledge in their own research activities, and the later usability of that knowledge by societal (non-scientific) agents, an effect that results from increasing its relative cognateness. This does not mean that all knowledge that is cognate to users will necessarily be taken up, or indeed will be useful, and as noted above we wish to avoid an input fallacy, that all knowledge that can potentially somehow be used is useful. But at the same time, we do argue that not all excellent research is equally cognate to eventual end users. Therefore quality of knowledge cognateness does clearly increase the capacity of that knowledge to be taken up by users or to be used (as the basis) for the generation of additional knowledge that will be more prone to be taken up by users.

We have therefore defined elsewhere (Olmos-Peñuela et al. 2014b) the property of academic openness as the extent to which academic researchers draw upon external knowledge (or include external interests) in their own research activities. Our operational definition of open research behaviour (derived from OlmosPeñuela et al., 2014b) is based around behaviours that demonstrate that a researcher incorporates user knowledge or interests into their research processes, which we here group into five distinct classes:

1. Reflection: the process of consolidating and reviewing past experiences and knowledge to define areas where there are gaps in existing and promising new routes forward as the basis for as yet undefined future research activities.

2. Inspiration: the process of seeing a challenging issue and translating that into a question which fits into a class of problems which the researcher is interested to address in their research.

3. Planning: the practicalities of planning a process by which resources are to be allocated in a logical way to progress from a question via analysis to new knowledge that answers that question.

4. Execution: implementing a research strategy to bring together existing resources and a research question around a robust methodology to sort out 'messy' real world data to give deeper insights.

5. Societal dissemination: making the knowledge available to others not immediately involved in that research to allow them to absorb it and utilise it as a resource in their own processes.

In each of these five processes, researchers may be more or less 'open' to outside knowledge by incorporating that outside knowledge into these processes; it is not that they do something different, rather that they carry out scientific processes in ways that incorporate external knowledge. We also build on the idea of a 'star scientist' (Zucker and Darby 1996), which has emerged to describe those scientists 
who make substantial contributions to their scientific field, and in the particular case of biotechnology, also laid the foundations for the growth of a huge industry around those technologies. We define by analogy open star scientists as those researchers whose research practices incorporating external knowledge into their own research activities, and hence maximising the cognateness of the newlycreated knowledge with those of socio-economic users. We define the class of open star scientists (hereafter star) as the group of researchers who are most 'open' (as defined above). Conversely, we define as 'non-open star scientists' (hereafter non-stars) as those researchers who not the most open.

Table 1 Descriptions of scientist open behaviour in five kinds of research process

\begin{tabular}{|c|c|c|}
\hline Research process & Description of research processes & Open behaviour at research processes \\
\hline Reflection & $\begin{array}{l}\text { Consolidating past experiences to } \\
\text { define future knowledge gaps and } \\
\text { identify future research domains. }\end{array}$ & $\begin{array}{l}\text { Having undertaken past research with external partners: the } \\
\text { researcher has experience in seeing problems in ways that } \\
\text { incorporate user knowledge. }\end{array}$ \\
\hline Inspiration & $\begin{array}{l}\text { Taking a practical challenge and } \\
\text { conceptualizing it as a problem } \\
\text { which their research can address. }\end{array}$ & $\begin{array}{l}\text { Being inspired by use conditions (what Stokes calls 'Edison' or } \\
\text { 'Pasteur'-type researchers): they may follow research questions } \\
\text { influenced by socio-economic considerations, choosing more } \\
\text { research questions leading to more usable knowledge }\end{array}$ \\
\hline Planning & $\begin{array}{l}\text { Setting out the steps by which } \\
\text { resources are allocated to answer } \\
\text { the research question. }\end{array}$ & $\begin{array}{l}\text { Being explicit in research proposal/ plans how external parties will } \\
\text { be involved: 'pro-social' behaviours are more likely to develop } \\
\text { research projects which create more usable knowledge (D'Este et } \\
\text { al. 2013). }\end{array}$ \\
\hline Execution & $\begin{array}{l}\text { Executing a research plan to create } \\
\text { new knowledge and insights that } \\
\text { address the initial research question. }\end{array}$ & $\begin{array}{l}\text { Involving external knowledge resources in project execution: this } \\
\text { affects the nature of the knowledge produced and thus makes it } \\
\text { more cognate with user knowledge. }\end{array}$ \\
\hline $\begin{array}{l}\text { Societal } \\
\text { dissemination }\end{array}$ & $\begin{array}{l}\text { Assisting external agents to absorb } \\
\text { the new knowledge produced in their } \\
\text { own processes. }\end{array}$ & $\begin{array}{l}\text { Dissemination activities involve interaction with users (co-creative } \\
\text { dissemination): users provide knowledge of how they use that } \\
\text { knowledge and hence their knowledge is incorporated into the } \\
\text { final outputs. }\end{array}$ \\
\hline
\end{tabular}

Source: authors' own design (following Olmos-Peñuela et al. 2014b).

\section{Characteristics that might be associated with openness}

In this paper we are concerned with understanding what influences open researchers (defined here in terms of their demonstrated open research behaviour) in different kinds of research processes thereby increasing the cognateness of knowledge to others, and facilitating its acquisition by eventual societal users. In so doing we consider which kinds of variable might influence researchers' behaviour, in terms of incorporating external knowledge at various research processes, and in particular, those for whom incorporating external knowledge - and hence demonstrating an open research behaviour - is common throughout the various kinds of research processes they undertake.

The overarching distinction we make is between personal and professional characteristics. We define professional characteristics as those that are related to the general way that the researcher's disciplinary community chooses to organise 
the business of science. These may relate to the field within which they are active; to the nature of the problem being studied (experimental vs hermeneutic); to the type of social agents showing interest for scientists' research; to whether users' engagement is formal (via licenses, spin-offs, etc.) or informal; to whether their field is dynamic; and to whether they are engaged in multidisciplinary research. Personal characteristics are those unique to the researcher, including age, gender, relative workplace seniority, individual non-scientific motivations for conducting research and what is important to them in their career.

\subsection{Professional characteristics associated with openness}

Professional characteristics are those that derive from the way that a community of scientists chooses to organise the business of knowledge creation and the wider environment within which individual scientists operate. The first set of characteristics which we argue are salient relates to the disciplinary norms of the fields within which researchers are active. Different fields incorporate users within their wider scientific governance and practice, such as in terms of defining research questions, publication norms and engagement activities. Some fields are for example organised towards creating usable knowledge, such as engineering, not simply in terms of involving users in research processes, but the definition of what constitutes a valid problem is to some extent defined by the extent to which it relates to an imminent real world problem. In recent debates over the creation of societal value, there has been a tendency to internalise a set of values in which science, technology, engineering and mathematics (STEM) are regarded as more useful than social sciences and humanities (SSH) (inter alia Olmos-Peñuela et al. 2014a; Benneworth 2015; Olmos-Peñuela et al. 2015). This leads us to the following hypothesis:

$\mathrm{H} 1 \mathrm{a}$ : Researchers involved in STEM disciplines are more open than those in SSH disciplines.

Related to this, the humanities in particular have come in for extended criticism because of their hermeneutic rather than experimental modes of knowledge creation, and their tendency to create understanding of particular individual situations rather than precise answers to questions (Brewer 2013; Small 2013). It is easier for technological fields to transfer their knowledge to other fields at the level of natural language, whilst in hermeneutic disciplines the knowledge is so interpretative in its nature that its validity is to some extent heavily dependent on the researcher themselves, it is their own reflective response to a phenomenon. A technological problem is one about which objective knowledge is useful and possible, whilst in humanistic knowledge production the positionality and subjectivity of the researcher makes that transferability much more difficult: this characteristic is what Hessels and Van Lente (2008) refer to as disciplinary finality. This leads us to the following hypothesis: 
H1b: Researchers involved in experimental disciplines are more open than those in hermeneutic disciplines.

The second set of characteristics we define relates to external linkages, that is, the kinds of connection with partners and the extent to which the knowledge exchange relationship creates a strong mutual interdependence between partners around creating knowledge that is individually exploitable by them. Therefore we argue that open behaviour may be associated with the nature of the external linkages that a researcher has with external users. Olmos-Peñuela et al. (2014a) made a distinction between formal activities, based on market transactions (e.g. patent licenses and consultancy) and informal activities (such as writing in newspapers, media appearances and other interactions). Formal linkages involve an economic transaction that indicates the user has acquired the rights to the knowledge, a signal that the user therefore believes that its acquisition is desirable and can usefully be combined to create value. Conversely, in informal relationships, this is more discretionary; it is without obligation and unrelated to knowledge combination-creation processes. Formal relationships can be understood as relating to 'need to know' knowledge whilst informal relationships relate to 'nice to know knowledge'. And whilst Bate (2011) may be able to anecdotally cite a number of examples where informal engagement is successfully incorporated in the business of knowledge creation, the existence of an underlying economic transaction demonstrates that a user has acquired the knowledge. This leads us to the following hypothesis:

$\mathrm{H} 2 \mathrm{a}$ : Researchers that primarily interacting with users through formal engagement activities are more open than those using primarily informal engagement activities.

With respect to this issue of an external user demonstrating the value of the knowledge by formally acquiring it, we also argue that working with user agents is indicative of openness. Although different kinds of users may acquire knowledge for different reasons, with firms seeking to solve problems, and governments more interested in understanding situations and trends, both those kinds of users still have to acquire and absorb that knowledge. Researchers that are receptive to outside interest from external agents are consequently more likely to develop cognateness with those users. In the case of the UK, for example, in the 2000s, the Ministry responsible for territorial development invested heavily in building a community of researchers who understood and could address their questions with a mix of funded projects, Ph.Ds, network meetings, and publications, a community who were receptive to their funders and created cognate knowledge. This is a specific example of users providing knowledge resources to their scientific partners to help them to solve their problems, and this is a characteristic that we would associate with openness. This leads us to the following hypothesis: 
$\mathrm{H} 2 \mathrm{~b}$ : Researchers that are aware of and receptive to more interests from external agents are more open than those that are less receptive and aware.

The third set of variables refers to the relative dynamism of the field in which researchers are involved, something identified by Van Rijnsoever et al. (2008) as influencing the way in which researchers choose to interact. Researchers in rapidly changing (dynamic) fields are confronted with new concepts, techniques, ideas and approaches, and therefore cannot afford to remain exclusively active in their existing disciplinary 'comfort zone'. The ability to deal with external knowledge becomes increasingly important to them, and therefore this increases their propensity to incorporate that external knowledge within their own research activities. This would therefore imply that those researchers in fields that are more dynamic would tend to be more open than researchers in fields where the business of science can proceed within the paradigm and without reference to external knowledges. This leads us to the following hypothesis:

H3a: Researchers in highly dynamic fields are more open than those in less dynamic fields.

Given that Van Rijnsoever et al. (2008) used an emergent definition of dynamism (asking researchers whether they were in a dynamic field), we refine their variable by distinguishing between two kinds of dynamism that may place pressure on researchers to seek out and incorporate different kinds of knowledge.

- Fields that are internally dynamic, where the scientific state-of-the-art is rapidly advancing, have to acquire new disciplinary knowledge to ensure their knowledge is able to make a contribution.

- Fields that are externally dynamic, where there are many new practical problems emerging demanding their attention and will need to follow these problems in order to remain well positioned.

This leads us to the following hypothesis pair:

H3a1: Researchers in highly internally dynamic fields are more open than those in less internally dynamic fields.

H3a2: Researchers in highly externally dynamic fields are more open than those in less externally dynamic fields.

A final characteristic which suggests that researchers may be using external knowledge, thereby increasing the valency and usability of their knowledge, is that of multidisciplinarity. Multidisciplinary as a mode of scientific governance emerges to address particular problems identified as being important, and which cannot be solved within a single disciplinary paradigm. This means that governance allocating resources, effort, interest and reward to research - therefore has to be done on the basis of a commonly agreed set of understandings, with people from 
different fields needing to be able to mutually comprehend what different actors are undertaking in the field. The fact that multidisciplinary research involves building cognateness and real world application leads us to argue that multidisciplinarity is associated with researchers' openness, and to the following hypothesis:

$\mathrm{H}_{3}$ : Researchers involved in multidisciplinary collaboration are more open than those only collaborating within a single disciplinary area.

\subsection{Personal characteristics associated with openness}

Although scientific agents are strongly conditioned by the professional landscapes within which they operate, there is also evidence to suggest that research processes are also affected by personal characteristics. A first personal characteristic is the gender of researchers. Van Rijnsoever and Hessels (2011) use gender as a predictor of multidisciplinarity, drawing on evidence from Rhoten and Pfirman (2007) of a higher propensity for working multidisciplinarily, as well as fitting with empirically identified female traits for team working, being better able to integrate diverse kinds of knowledge and networking activities. On that basis, one might expect female researchers to therefore be involved in knowledge creation processes that are more easily integrated with knowledge creation in other domains, making them more open, and hence leading to our first hypothesis relating to personal characteristics:

H4a: Female researchers are more open than male researchers.

The second personal characteristic is the period of academic formation. There has been a shift in the last quarter century from the key principles of science being around the pursuit of fundamental knowledge to the prosecution of entrepreneurial science (creating 'useful' knowledge). We would therefore expect that those researchers whose academic identities were formed more recently would be more oriented towards the ideals of entrepreneurial science than those whose academic identities were formed in the age of the mass democratic university (Delanty 2002). Stephan and Levin (1993) noted that age tends to be negatively associated with research excellence and there might also be an effect that older researchers have a lower resource dependency than younger researchers in terms of external knowledge resources. This leads us to the following hypothesis:

$\mathrm{H} 4 \mathrm{~b}$ : Researchers who were formed in the age of entrepreneurial science are more open than those formed in the age of the ivory tower.

The final personal characteristic relates to the extent to which non-scientific considerations play a role in their academic workplace identity. Roach and 
Sauermann (2010) highlight that researchers who are interested in salary and labour protection tend to ensure that they can move into industry if necessary to support their labour conditions. Conversely, those that are interested in the pursuit of scientific knowledge will remain in the field, for which academic publication activity is necessary. We interpret this to mean that researchers for whom working conditions are more important than scientific novelty in their careers are more likely to maintain cognateness with potential users than those whose primary concerns relate to creating new knowledge through interesting research projects. This leads us to the following hypothesis:

H4c: Researchers who are more focused on working conditions are more open than researchers who are more focused on contributing to scientific advance.

\section{Data and Methodology}

\subsection{Data collection and population}

Our empirical analysis focuses on the Spanish Council for Scientific Research (hereafter CSIC), which is the largest public research organisation in Spain, with more than 14,000 employees and 126 research institutes covering the following eight areas of knowledge: humanities and social sciences; biology and biomedicine; food science and technology; materials science and technology; physical science and technology; chemical science and technology; agricultural sciences; and natural resources (CSIC 2012). Given that the explanation about the data collection, population and sample have been provided with greater details elsewhere (Olmos-Peñuela et al. 2014a); for succinctness, here we focus on the most pertinent information for our empirical study.

Our study population is all CSIC researchers holding a doctoral degree, with the right to be principal investigators and to engage in contracts and agreements with external parties. This population includes both contracted post-doctoral and civil servants, and accounts for 4,240 researchers. Our data come from the IMPACTO project conducted in 2011 aimed at analysing the societal impact of public funded research and were collected via an online questionnaire implemented and answered by CSIC researchers. The data collection process included email reminder and telephone follow-up that helped to ensure a final sample proportionally distributed by professional categories and areas of knowledge. Thus, the final sample was made up 1,583 researchers (37\% of the population).

The questionnaire included information of a range of aspects related to researchers' profile and activities, their external linkages (in terms of type of external users interested in academic research, mechanism for collaboration, motivations, impediments and results of the collaborations) and dissemination activities. As the following section shows, IMPACTO data allows measuring open research behaviour at the different research processes previously identified $(c f$. 
Olmos-Peñuela et al. 2014b) alongside with their professional and personal characteristics.

\subsection{Variables}

The hypotheses presented in Section 4 are tested with a number of variables that can be classified into the following 3 groups namely: a) openness; b) professional characteristics; and c) personal characteristics.

\section{a) Openness}

To operationalise our definition of 'openness', following Olmos-Peñuela et al. (2014b), we identify indicators of open research behaviours at each of the five research processes presented in Section 3 namely reflection, inspiration, planning, execution and societal dissemination. The operational definitions and descriptive statistics of the variables measuring 'openness' at these research processes are presented in Table 2 .

Table 2. Operational definitions and descriptive statistics of 'openness' in different research processes

\begin{tabular}{|c|c|c|c|}
\hline Continuous variables & Measure & Sub-items & $\begin{array}{l}\text { Method and } \\
\text { descriptive } \\
\text { statistics } \\
\end{array}$ \\
\hline $\begin{array}{l}\text { Openness during } \\
\text { planning processes }\end{array}$ & $\begin{array}{l}\text { Measured as an index on a Likert scale of } \\
\text { frequency ranging from } 1 \text { (never) to } 4 \text { (regularly) } \\
\text { regarding frequency with which the researcher } \\
\text { engages in each of the following activities when } \\
\text { conducting a research project. The scores of the } \\
\text { respondents, which initially ranged from } 3 \text { to } 12 \text {, } \\
\text { were weighted in order to take into account 'does } \\
\text { not apply' answers. Thus, for each respondent, the } \\
\text { sum of the score was divided by the number of } \\
\text { applicable item(s). Even though the initial index has } \\
\text { integer values from } 1 \text { to } 4, \text { once weighted, it can } \\
\text { take on non-integer values. }\end{array}$ & $\begin{array}{l}\text { - Identify the potential results of your } \\
\text { research that can benefit users } \\
\text { Identify the potential users who } \\
\text { can apply the results of your } \\
\text { research } \\
\text { Identify intermediaries in order to } \\
\text { transfer the results of your results }\end{array}$ & $\begin{array}{l}\text { Sum of the three } \\
\text { items divided by the } \\
\text { number of applicable } \\
\text { items } \\
\text { Range: } 1-4 \\
\text { Mean: } 2.52 \\
\text { S.D: } 0.73 \\
\text { Cronbach's } \alpha: 0.78\end{array}$ \\
\hline \multirow[t]{2}{*}{$\begin{array}{l}\text { Openness during } \\
\text { execution processes }\end{array}$} & $\begin{array}{l}\text { Measured as an index on a Likert scale of } \\
\text { frequency ranging from } 1 \text { (not important) to } 4 \text { (very } \\
\text { important) regarding the degree of importance the } \\
\text { researcher attaches to each of the following items, } \\
\text { as reason for interacting with external entities } \\
\text { (firms, public government agencies, non-profit } \\
\text { organisations). The scores of the respondents, } \\
\text { which initially ranged from } 4 \text { to } 16 \text {, were weighted in } \\
\text { order to take into account 'does not apply' answers. } \\
\text { Thus, for each respondent, the sum of the score } \\
\text { was divided by the number of applicable item(s). } \\
\text { Even though the initial index has integer values } \\
\text { from } 1 \text { to } 4 \text {, once weighted, it can take on non- } \\
\text { integer values. }\end{array}$ & $\begin{array}{l}\text { - To keep abreast of about the areas } \\
\text { of interest of these non-academic } \\
\text { entities } \\
\text { - To test the feasibility and practical } \\
\text { application of your research } \\
\text { - To obtain information or materials } \\
\text { necessary for the development of } \\
\text { - Tour current lines of research } \\
\text { To explore new lines of research }\end{array}$ & $\begin{array}{l}\text { Sum of the four items } \\
\text { divided by the } \\
\text { number of applicable } \\
\text { items }\end{array}$ \\
\hline & Description & & $\begin{array}{l}\text { Descriptives } \\
\% \text { of '1' }\end{array}$ \\
\hline $\begin{array}{l}\text { Openness during } \\
\text { reflection processes }\end{array}$ & \multicolumn{2}{|c|}{$\begin{array}{l}\text { Coded ' } 1 \text { ' if the researcher has experienced changes or substantial changes in the past research } \\
\text { agenda as a result of the relationships with non-academic entities, and '0' otherwise. }\end{array}$} & $27.8 \%$ \\
\hline $\begin{array}{l}\text { Openness during } \\
\text { inspiration processes }\end{array}$ & \multicolumn{2}{|c|}{$\begin{array}{l}\text { Coded ' } 1 \text { ' if the researcher scientific activity was inspired or substantially inspired by the practical } \\
\text { use and/or application of knowledge outside the academic environment, and '0' otherwise. }\end{array}$} & $71.4 \%$ \\
\hline
\end{tabular}




\begin{tabular}{ll}
\hline $\begin{array}{l}\text { Openness during } \\
\text { dissemination processes }\end{array}$ & $\begin{array}{l}\text { Coded '1' if the researcher, as a result of collaborating with non-academic entities, reported as } \\
\text { important or very important the following three results identified as co-creative dissemination } \\
\text { activities they got: 1) obtaining patents or other intellectual property right; 2) developing } \\
\text { exhibitions and/or exhibition catalogues; generating clinical guidelines, standards, and 3) codes } \\
\text { of practices), and '0' otherwise. }\end{array}$ \\
\hline $\begin{array}{l}\text { Source: Olmos-Peñuela et al. (2014b), following Weingart (2009), we have used this table already when publishing on this } \\
\text { database. }\end{array}$
\end{tabular}

Indicators for open research behaviours can be found over the different research processes in which scientists are involved when developing research projects ( $c f$. Table 1). Researchers can behave in an open way during all the research processes or just at some of those research processes. In this study we are interested in capturing the open star scientists (our stars) - i.e. the most open researchers of our sample, understood as those continuously incorporating external knowledge in their research activities ( $c f$. Section 3). Thus, our focus is on those researchers demonstrating a systematic open behaviour over the research processes. In so doing, we use a two-step procedure to construct a new variable ('open count') that counts the number of processes during which the researcher has demonstrated an open research behaviour:

- First, we transformed the 'openness' continue variables (i.e. during planning and execution processes) into binary variables that distinguish the highest ranked researchers in terms of open research behaviour (i.e. those ranked at the top $50 \%$ of the sample), from the lowest ranked (the lowest $50 \%$ of the sample) for each of these variables. More details about the distributions of the binary variables corresponding to open research behaviours during the planning and execution processes are provided in Table 3.

- Second, we used the three original binary variables (i.e. during reflection, inspiration and dissemination processes) and, along with the two new binary variables previously built (those referred to planning and execution processes), we created an ordinal variable named open count - ranging from 0 to 5 - measuring the number of processes during which open research behaviours can be identified.

The distribution of the variable labelled open count indicates that $6.6 \%$ of the sample analysed demonstrated openness during all the 5 research processes, whereas $22.9 \%$ did it in at least 4 processes, and $48.2 \%$ in at least 3 processes. Since we are interested in identifying stars, we focused on the top quarter of the sample as representing those whose research behaviour is open in a substantial number of research processes (4 or more). There is a degree of pragmatism in our choice in that it gives a group of open stars who represent around one quarter of the sample, but at the same time it captures those who are 'open dominant' in most of their research processes. Therefore, we created the binary variable labelled star that identifies the $22.9 \%$ of the researchers of the sample being open in at least 4 
processes $^{5}$. A summary of the descriptive statistics of all the above variables related to 'openness' is presented in Table 3.

Table 3. Descriptive statistics for 'openness' variables

\begin{tabular}{|c|c|c|c|c|c|}
\hline Openness variables & $\begin{array}{l}\text { Type of } \\
\text { variable }\end{array}$ & Range & $\%$ Yes & $\begin{array}{l}\text { Mean } \\
\text { (SD) }\end{array}$ & $\begin{array}{c}a \\
\text { Cronbach }\end{array}$ \\
\hline During reflection processes & Binary & $0-1$ & $27.8 \%$ & & \\
\hline During inspiration processes & Binary & $0-1$ & $71.4 \%$ & & \\
\hline During planning processes & Continuous & $1-4$ & & $\begin{array}{c}2.52 \\
(0.73)\end{array}$ & 0.78 \\
\hline During execution processes & Continuous & $1-4$ & & $\begin{array}{c}3.11 \\
(0.55)\end{array}$ & 0.71 \\
\hline During dissemination processes & Binary & $0-1$ & $28.5 \%$ & & \\
\hline During planning processes (top 50\%) & Binary & $0-1$ & $48.9 \%$ & & \\
\hline During execution processes (top 50\%) & Binary & $0-1$ & $50.0 \%$ & & \\
\hline Open count & Ordinal & $0-5$ & $\begin{array}{l}0 \text { processes: } 10.3 \% \\
1 \text { process: } 19.1 \% \\
2 \text { processes: } 22.4 \% \\
3 \text { processes: } 25.3 \% \\
4 \text { processes: } 16.3 \% \\
5 \text { processes: } 6.6 \%\end{array}$ & & \\
\hline Star & Binary & $0-1$ & $22.9 \%$ & & \\
\hline
\end{tabular}

\section{b) Professional characteristics}

The professional characteristics considered in our empirical analysis are related with disciplinary norms (fields), external linkages (nature and type of external agent), dynamism of the field and multidisciplinarity. These characteristics have been measured through the 10 variables presented with more detail in Table 4.

Regarding disciplinary norms, our sample is made up by $7.4 \%$ of researchers belonging to the area of SSH and 92.6\% conducting research within STEM fields. When the distinction is made between hermeneutic and experimental fields, only $4.9 \%$ of the sample is categorised as humanistic, as opposed to the $95.1 \%$ labelled as experimental. For external linkages, $43.3 \%$ of the pathways used by researchers to stablish collaboration with external parties were formal. Among the type of external agents, government agencies were the type of agent that researchers reported as the most interested in their academic research results $(41.1 \%)$, followed by firms (32.6\%), international organisms (29.8\%) and non-profit organisations (20.8\%). Regarding the dynamism in the field, internal dynamism was reported as the most important with $96.7 \%$ of researchers considering that contributing to knowledge advance was important or very important. Conversely, external dynamism was less relevant, with $64 \%$ of researchers reporting as 
important or very important contributing to the resolution of socio-economic problems. Finally, 28.8\% of the sample is multidisciplinar, since they reported to usually conduct their research with researchers belonging to other scientific disciplines.

Table 4. Descriptive statistics for the variables measuring professional characteristics

\begin{tabular}{|c|c|c|}
\hline Binary variables & Description & $\begin{array}{l}\text { Descriptives } \\
\% \text { of ' } 1 \text { ' }\end{array}$ \\
\hline $\mathrm{SSH}$ & $\begin{array}{l}\text { Binary variable coded ' } 1 \text { ' if the researcher belongs to the area of Social Science and } \\
\text { Humanities (SSH), otherwise '0'(STEM) }\end{array}$ & $7.4 \%$ \\
\hline Hermeneutic & $\begin{array}{l}\text { Binary variable coded ' } 1 \text { ' if the researcher belongs to the area of Humanities }(H) \text {, otherwise ' } 0 \text { ' } \\
\text { (Experimental: SS+STEM)'. }\end{array}$ & $4.9 \%$ \\
\hline Firm & $\begin{array}{l}\text { Binary variable coded ' } 1 \text { ' if researcher reports that firms are interested or significantly } \\
\text { interested in its research, otherwise ' } 0 \text { '. }\end{array}$ & $32.6 \%$ \\
\hline Government agencies & $\begin{array}{l}\text { Binary variable coded ' } 1 \text { ' if researcher reports that government agencies are interested or } \\
\text { significantly interested in its research, otherwise ' } 0 \text { '. }\end{array}$ & $41.1 \%$ \\
\hline $\begin{array}{l}\text { Non-profit organizations } \\
\text { (NPOs) }\end{array}$ & $\begin{array}{l}\text { Binary variable coded ' } 1 \text { ' if researcher reports that non-profit organizations are interested or } \\
\text { significantly interested in its research, otherwise ' } 0 \text { '. }\end{array}$ & $20.8 \%$ \\
\hline International organisms & $\begin{array}{l}\text { Binary variable coded ' } 1 \text { ' if researcher reports that international organisms are interested or } \\
\text { significantly interested in its research, otherwise ' } 0 \text { '. }\end{array}$ & $29.8 \%$ \\
\hline Multidisciplinarity & $\begin{array}{l}\text { Binary variable coded ' } 1 \text { ' if researcher reports usually conducting research with researchers } \\
\text { from other scientific disciplines, otherwise ' } 0 \text { '. }\end{array}$ & $28.8 \%$ \\
\hline Continuous variable & Description & $\begin{array}{l}\text { Mean (SD) } \\
\text { Range }\end{array}$ \\
\hline Formal engagement & $\begin{array}{l}\text { The percentage of the formal pathways used by a researcher to collaborate with non-academic } \\
\text { agents to the total pathways used over the last three years (more details in Olmos-Peñuela et } \\
\text { al. 2014a). }\end{array}$ & $\begin{array}{c}43.3(17.94) \\
1-100\end{array}$ \\
\hline Ordinal variable & Description and distribution of the variable & $\begin{array}{l}\text { Mean (SD) } \\
\text { Range } \\
\text { Distribution (\%) }\end{array}$ \\
\hline Internal dynamic field & $\begin{array}{l}\text { Researcher reports that to contribute to knowledge advance in the field is: } \\
\text { - } \text { Not important }(=1) \\
\text { - } \quad \text { Slightly important }(=2) \\
\text { - } \quad \text { Very important }(=3) \\
\text { - }\end{array}$ & $\begin{array}{l}3.7(0.50) \\
(1-4) \\
0.3 \% \\
3.0 \% \\
15.4 \% \\
81.3 \% \\
\end{array}$ \\
\hline External dynamics field & $\begin{array}{l}\text { Researcher reports that to contribute to the resolution of socio-economic problems is: } \\
\begin{array}{ll}\text { - } & \text { Not important }(=1) \\
\text { - } & \text { Slightly important }(=2) \\
\text { - } & \text { Important }(=3) \\
& \text { Very important }(=4)\end{array}\end{array}$ & $\begin{array}{l}2.8(0.97) \\
1-4 \\
9.6 \% \\
26.4 \% \\
32.1 \% \\
31.9 \%\end{array}$ \\
\hline
\end{tabular}

a Means, SD and range are provided for ordinal variables for practical purposes, for the comparison presented in Table 6.

\section{c) Personal characteristics}

The personal characteristics of the sample analysed are presented in Table 5 . The sample is slightly skewed towards men (62.1\%), with women representing $37.9 \%$. The average age of the overall sample is 48 years old and is distributed according to 4 academic ranks as follows: post-doctoral contracted researchers $(18.1 \%)$; tenured scientists (36.4\%); scientific researchers (27.2\%); and researcher professors (18.3\%). Finally, the average respondent valued as 2.8 (in a range from 1 to 4 ) the relevance assigned to its working conditions in terms of salary and job security. 
Table 5. Descriptive statistics for personal characteristics variables

\begin{tabular}{|c|c|c|}
\hline $\begin{array}{l}\text { Binary or Categorical } \\
\text { variable }\end{array}$ & Description & $\begin{array}{c}\text { Descriptives } \\
\% \text { of ' } 1 \text { ' }\end{array}$ \\
\hline Gender & Binary variable coded ' 1 ' if the researcher is a woman, otherwise ' 0 ' (man). & $37.9 \%$ \\
\hline Seniority & $\begin{array}{l}\text { According to the four academic position researchers can hold in the CSIC, the sample is } \\
\text { distributed as follows: } \\
\text { - Doctoral contracted scientist } \\
\text { - Tenured scientist } \\
\text { - Scientific researcher } \\
\text { - Researcher professor }\end{array}$ & $\begin{array}{l}18.1 \% \\
36.4 \% \\
27.2 \% \\
18.3 \%\end{array}$ \\
\hline Continuous variable & Description & $\begin{array}{l}\text { Mean (SD) } \\
\text { Range }\end{array}$ \\
\hline Age & Age of the researcher in 2011 & $\begin{array}{c}48.1(9.40) \\
28-71\end{array}$ \\
\hline Working conditions & $\begin{array}{l}\text { Measured as an index on a Likert scale ranging from } 1 \text { (not important) to } 4 \text { (very important) for } \\
\text { degree of importance researcher attaches in its work to: } \\
\text { - Salary } \\
\text { - Job security } \\
\text { Scores initially ranged from } 2 \text { to } 8 \text {. To account for 'does not apply' answers, each respondent's } \\
\text { index was calculated as arithmetic mean of applicable sub-items divided by number of } \\
\text { applicable sub-items (a Cronbach: } 0.62 \text { ). }\end{array}$ & $\begin{array}{c}2.8(0.75) \\
1-4\end{array}$ \\
\hline
\end{tabular}

\subsection{Analysis and test considerations}

As discussed above, our aim is to understand whether a number of professional and personal characteristics are associated with star researchers. In so doing, hypotheses have been presented in Section 4 and are tested using different statistical tests, depending on the nature of the variables.

- The t-test is used for assessing the hypotheses in which continuous variables (following a normal distribution) are used to capture professional and personal researchers' characteristics - i.e. nature of the collaboration $(\mathrm{H} 2 \mathrm{a})$, age $(\mathrm{H} 4 \mathrm{~b})$ and working conditions ( $\mathrm{H} 4 \mathrm{c}$ ).

- The Mann-Whitney test (U) is applied for the hypotheses in which ordinal variables are used to measure professional or personal characteristics - i.e. dynamism ( $\left.\mathrm{H}_{\mathrm{a} 1} \& \mathrm{H}_{\mathrm{a} 2}\right)$.

In both t-test and Mann-Whitney test, the null hypothesis is that there are no differences between star and non-star researchers for the professional and personal characteristics considered, and the hypothesis is rejected if the p-value is lower than 5\%. Both tests allow assessing whether there are statistically significant differences between star and non-star researchers

- The Chi square test $(\chi 2)$ is used to assess the hypotheses where variable measuring the professional or personal characteristics are binary or categorical -i.e. disciplinary norms $(\mathrm{H} 1 \mathrm{a}, \mathrm{H} 1 \mathrm{~b})$, type of external partners interested in research $(\mathrm{H} 2 \mathrm{~b})$, multidisciplinarity $(\mathrm{H} 3 \mathrm{~b})$, gender $(\mathrm{H} 4 \mathrm{a})$ and seniority $(\mathrm{H} 4 \mathrm{~b})$. The $\chi 2$ tests whether the independence or not between star and non-star researchers regarding the abovementioned characteristics, been the null hypothesis of independence rejected if the p-value is lower than $5 \%$. 
Test results are presented in the following Section 6.

\section{Results}

The hypotheses presented in Section 4 have being empirically tested and are presented in Table 6 (for professional characteristics) and Table 7 (for personal characteristics).

Overall, we find no evidence to back up the assertion that personal characteristics (in terms of gender, age, seniority, and values related to working conditions) differ between star and non-star researchers. Indeed, differences emerge when we turn our focus into the professional characteristics.

Regarding professional characteristics, disciplinary norms have been tested comparing SSH vs. STEM (H1a), and hemeneutic vs. experimental (H1b). For these two hypotheses, we cannot reject the null hypothesis since we get p-values higher than $5 \%$ (.550 and .272, respectively).

Statistical differences are supported when analysing researchers' external linkages and its nature. Indeed, star researchers use wider formal pathways of interaction to collaborate with external agents than non-star researchers ( $p$-value=.000). When focusing on the type of external agents interested in researchers' investigation $(\mathrm{H} 2 \mathrm{~b})$, we found that all the external partners (except government agencies) are more interested in research conducted by star researchers than by non-star researchers. These results partially validate our initial hypotheses proposing that stars collaborate more with external agents than non-stars; except for the case of collaborations with governmental agencies - where no differences are found between star and non-star researchers.

For the hypotheses regarding the field dynamism, our empirical results do not support differences for internal dynamism ( $p$-value $=.827$ ) but for external dynamism ( $\mathrm{p}$-value $=.000$ ). Thus, our hypothesis about the higher dynamism of the fields of star researchers is partially supported since we find that stars are located in field within higher pressures to contribute to socio-economic problems, and then experiencing higher external changes and dynamisms in their fields.

The last professional characteristic considered is researchers' multidisciplinarity. Results indicate that star researchers usually collaborate more with researchers from other disciplines compared to non-star researchers ( $p$-value=.000). This empirical result sustains our initial hypothesis (H3b) presented in Section 4.

Regarding personal characteristic $\left(\mathrm{H} 4_{\mathrm{a}, \mathrm{b}, \mathrm{c}}\right)$, we do not find evidences to reject the null hypothesis that star researchers shares the same characteristics than non-star researchers. This implies that none of the hypotheses presented in Section 4 for personal characteristics are supported. These results could be interpreted in the 
sense that, demonstrating 'openness' throughout the different research processes does not seem to be associated with researchers' personal characteristic linked to the gender, age, seniority, or work conditions. 
Table 6. Results of statistical test about differences between star and non-star researchers regarding professional characteristics

\begin{tabular}{|c|c|c|c|c|c|c|}
\hline Hypotheses & Professional characteristics & $\begin{array}{l}\text { Values for non-star } \\
\text { (means or distributions) }\end{array}$ & $\begin{array}{c}\text { Values for star } \\
\text { (means or distributions) }\end{array}$ & Statistics & p-values & Results \\
\hline $\mathrm{H} 1_{\mathrm{a}}$ & Field (SSH vs STEM) & $\begin{array}{l}\text { SSH: } 7.6 \% \\
\text { STEM: } 92.4 \%\end{array}$ & $\begin{array}{l}\text { SSH: } 8.7 \% \\
\text { STEM: } 91.3 \%\end{array}$ & Chi-Square & 0.550 & No differences \\
\hline $\mathrm{H} 1_{\mathrm{b}}$ & Hermeneutic vs Experimental & $\begin{array}{l}\text { Hermeneutic: } 4.7 \% \\
\text { Experimental: } 95.3 \%\end{array}$ & $\begin{array}{l}\text { Hermeneutic: } 6.3 \% \\
\text { Experimental: } 93.7 \%\end{array}$ & Chi-Square & 0.272 & No differences \\
\hline $\mathrm{H} 2 \mathrm{a}$ & $\%$ Formal engagement & $42.64 \%$ & $46.80 \%$ & t-test & 0.000 & Formal NON-STAR $<$ Formal STAR ${ }^{* * *}$ \\
\hline $\mathrm{H} 2 \mathrm{~b}$ & Firms & $28.1 \%$ & $62.5 \%$ & Chi-Square & 0.000 & Firms NON-STAR $<$ FirmS STAR ${ }^{* \star *}$ \\
\hline $\mathrm{H} 2 \mathrm{~b}$ & Government agencies & $41.8 \%$ & $46.7 \%$ & Chi-Square & 0.138 & No differences \\
\hline $\mathrm{H} 2 \mathrm{~b}$ & Non-profit organisations & $19.0 \%$ & $31.5 \%$ & Chi-Square & 0.000 & NPO NON-STAR $<$ NPO STAR ${ }_{\text {ST** }}^{* \star *}$ \\
\hline $\mathrm{H} 2_{\mathrm{b}}$ & International organisations & $27.9 \%$ & $41.0 \%$ & Chi-Square & 0.000 & Intern NON-STAR $<$ Intern STAR ${ }^{* * *}$ \\
\hline $\mathrm{H} 3 \mathrm{a} 1$ & $\begin{array}{l}\text { Internal dynamism: pressure } \\
\text { to advance knowledge }\end{array}$ & $3.77^{a}$ & $3.78^{a}$ & $\begin{array}{l}\text { Mann- } \\
\text { Whitney }\end{array}$ & 0.827 & No differences \\
\hline $\mathrm{H} 3_{\mathrm{a} 2}$ & $\begin{array}{l}\text { External dynamism: pressure } \\
\text { to solve social problems }\end{array}$ & $2.80^{a}$ & $3.42^{\mathrm{a}}$ & $\begin{array}{l}\text { Mann- } \\
\text { Whitney }\end{array}$ & 0.000 & Ext-Dynam NON-STAR $<$ Ext-Dynam STAR ${ }^{* * *}$ \\
\hline $\mathrm{H} 3_{\mathrm{b}}$ & Multidisciplinarity & $26.2 \%$ & $45.7 \%$ & Chi-Square & 0.000 & MultidisC NON-STAR $<$ MultidisC STAR ${ }^{* * *}$ \\
\hline
\end{tabular}

${ }^{a}$ Means are provided for ordinal variables for practical purposes: they indicate direction of differences between star and non-star researchers.

Table 7. Results of statistical test about differences between star and non-star researchers regarding personal characteristics

\begin{tabular}{|c|c|c|c|c|c|c|}
\hline Hypotheses & Personal characteristics & $\begin{array}{l}\text { Values for non-star } \\
\text { (means or distributions) }\end{array}$ & $\begin{array}{c}\text { Values for star } \\
\text { (means or distributions) }\end{array}$ & Statistics & p-values & Results \\
\hline $\mathrm{H} 4 \mathrm{a}_{\mathrm{a}}$ & Gender & $\begin{array}{l}\text { Male: } 63.2 \% \\
\text { Female: } 36.8 \%\end{array}$ & $\begin{array}{l}\text { Male: } 63.0 \% \\
\text { Female: } 37.0 \%\end{array}$ & Chi-Square & 0.939 & No differences \\
\hline $\mathrm{H} 4_{\mathrm{b}}$ & Age & 48.8 & 49.1 & t-test & 0.648 & No differences \\
\hline $\mathrm{H} 4_{b}$ & Seniority & $\begin{array}{l}\text { Post-doctoral: } 14.6 \% \\
\text { Tenured scientist: } 37.4 \% \\
\text { Scientific researcher: } 29.2 \% \\
\text { Researcher professor: } 18.9 \%\end{array}$ & $\begin{array}{l}\text { Post-doctoral: } 15.7 \% \\
\text { Tenured scientist: } 36.7 \% \\
\text { Scientific researcher: } 25.3 \% \\
\text { Researcher professor: } 22.3 \%\end{array}$ & Chi-Square & 0.424 & No differences \\
\hline $\mathrm{H} 4_{\mathrm{c}}$ & Working conditions & 2.82 & 2.90 & t-test & 0.134 & No differences \\
\hline
\end{tabular}




\section{Discussion}

In this paper we have been concerned with trying to understand the characteristics of those scientists who are open to making their research usable by end users (an antecedent to those terminal knowledge transfers). In particular we have sought to critically explore the stereotype that often seems to emerge in a grey area of the literature, between research and practice, of the 'engaged academic entrepreneur', which has become a proxy for the kinds of academics whose research has the potential to contribute to society. By framing it in terms of researchers engaging in terminal knowledge transfer, there has been a tendency to frame the 'engagement heroes' of science as being those in disciplines and sectors which creates analytic knowledge that can easily be protected and exploited in contractual transactions.

This has become elided with a sense that these kinds of researchers are somehow more laudable in the context of science systems facing increasing pressures to ensure that those scientific investments deliver clear societal benefits. Our argument is that it is not just those scientists engaged with terminal knowledge transfer that are creating societally valuable knowledge rather that it is those who undertake excellent research that is cognate with users whose research will contribute to these terminal knowledge transfer. This provides us with a means to critically interrogate the stereotypical 'engagement hero', and create a more nuanced picture of who these scientists are (a summary of the results is presented in Table 8 below).

Table 8. Summary of professional characteristics differences between star and non-star researchers

\begin{tabular}{|c|c|c|}
\hline Hypotheses & Professional characteristics & Results \\
\hline $\mathrm{H} 1_{\mathrm{a}}$ & Field (SSH vs STEM) & No differences \\
\hline $\mathrm{H} 1_{\mathrm{b}}$ & Hermeneutic vs Experimental & No differences \\
\hline $\mathrm{H} 2_{\mathrm{a}}$ & $\%$ Formal engagement & Formal NON-STAR $<$ Formal STAR ${ }^{* * *}$ \\
\hline $\mathrm{H} 2 \mathrm{~b}$ & Firms & Firms NON-STAR $<$ Firms STAR *** \\
\hline $\mathrm{H} 2 \mathrm{~b}$ & Government agencies & No differences \\
\hline $\mathrm{H} 2 \mathrm{~b}$ & Non-profit organisations & NPO NON-STAR $<$ NPO STAR ${ }^{* * * *}$ \\
\hline $\mathrm{H} 2 \mathrm{~b}$ & International organisations & Intern NON-STAR $<$ Inter STAR ${ }^{* * *}$ \\
\hline $\mathrm{H} 3_{\mathrm{a} 1}$ & Internal dynamism: pressure to advance knowledge & No differences \\
\hline $\mathrm{H} 3 \mathrm{a} 2$ & External dynamism: pressure to solve social problems & Ext-dynam NON-STAR $<$ Ext-dynam STAR ${ }^{* * *}$ \\
\hline$H 3 b$ & Multidisciplinarity & MultidisC NON-STAR $<$ MultidisC STAR ${ }^{* * *}$ \\
\hline
\end{tabular}

Part of these results does at least partly confirm the initial view of the researchers creating the most usable research. One characteristic of more open researchers (stars) is that they have a higher share of their engagements with society partners via formal 
mechanisms than for non-star researchers: these formal mechanisms are contractual arrangements such as spin-offs, patent licensing or consultancy. Likewise, those that regard themselves as working in fields where there is a high degree of societal pressure to create advances (such as health care or energy) are also those that are more open. Working with firms is also strongly associated with researchers' openness. Finally, those working in multidisciplinary environments - often associated with trying to find different perspectives to solve problems that traditional disciplinary communities cannot adequately address, are more open than those that self-identify as monodisciplinary.

But at the same time, we see evidence that suggests that we should get beyond the picture of the white-coated biotechnology entrepreneur-academic as being the driver of science's societal contributions. Table 8 highlights that there is far more scientists making a societal contribution than this one-size-fits-all stereotype. Perhaps most interesting is that we found no evidence that there were any disciplinary differences, with SSH researchers behaving just as open in their practices as STEM researchers despite a tendency amongst policy-makers to see STEM as being more useful than SSH (Olmos-Peñuela et al. 2014a). Likewise, there was no difference between the different epistemologies that researchers used, with researchers rooted in interpretative epistemologies being as open to outside knowledge as those using explanatory epistemologies. What was also interesting was that working with both non-profit and international organisations - something which is much more typically associated with the 'softer' disciplines of SSH - was associated with openness. That is unsurprising, but emphasises that market transactions are not the only way that usable knowledge is utilised by society to improve societal conditions.

A final element is that we did not find any evidence to suggest that personal characteristics were associated with increased openness, whether gender, age, job position or working conditions. Bringing these together, we see that although there are some characteristics that define open researchers, such as more formal than informal engagements, and engagement with firms, non-profit and international organisations, there are also some areas where there is a huge diversity. The fact that disciplinary area and epistemology does not affect open research behaviours is perhaps at odds with the policy stereotype of the engaged entrepreneurial engineer, and the idea that STEM subjects are more useful for society.

\section{Conclusions}

In the context of a special issue regarding getting beyond 'one-size-fits-all' narratives of science, our research provides a clear suggestion that there is no 'one-size-fits-all' concerning scientists creating the most usable knowledge that best contributes to socioeconomic advance. In particular, it is not just scientists engaged in terminal knowledge transfer that maximise system outputs, but those involved in open behaviours; scientists from all research backgrounds and with different methodologies that are behaving 
openly, and hence creating usable knowledge. This subtle distinction does not appear to be fully reflected by contemporary discourses, and we argue that more consideration need be given to the implications regarding which kinds of scientist make the most contribution to this societal knowledge pool.

We acknowledge that this is an exploratory piece of research however it provides some clues and evidence in the following direction. In the absence of evidence to reject our null hypotheses, we can infer that personal characteristics do not affect the propensity to include user knowledge systematically in the research process; this in turn suggests that the open star researchers in terms of creating usable knowledge are found across the academic domain with a wide variety of gender, age, academic position and commitment towards remaining in academic employment. Likewise, we find no evidence to reject the hypothesis that disciplinarity matters, with no differences in open research behaviour patterns between researchers in STEM fields and those in SSH, and similarly, between researchers in fields facing pressure to advance knowledge, and other researchers. We also find no evidence that might back Gulbrandsen's (2012) argument that those who are interested in their financial situation are more likely to be highly open.

However, we have also found a number of factors that are associated with those individuals who are incorporating user knowledge into their knowledge creation activities. Perhaps unsurprisingly, those who are in fields which feel pressure to solve societal problems are leading in terms of openness. Likewise, those that have a preponderance of formal rather than informal user connections are more likely to be open, as these are the scientists who are receiving signals - through formal transactions - that their research is usable, thereby validating their knowledge trajectory. Moreover, those that have a significant relationship with firms, international organisations and non-profit organisations are more open, suggesting that creating understanding and framing knowledge requires a cognateness with users' interests and needs that are associated with openness.

What our results seem to suggest is that openness is associated with scientists receiving signals from outside the field that the created knowledge is valuable. This is not just a question of user knowledge driving knowledge creation processes, but also the existence of signals from other disciplines that there is a value in what is being done. From our findings, we infer that those scientists that receive external signals are also those who respond to those signals, and this makes them more responsive. So our first contention is that more consideration needs to be given to this signalling process, to understand how this functions in practice, and the effect that this has on the academics behaviours, norms and practices of those involved in creating usable knowledge. But of course, these "signals" are received by academics in a variety of different ways reflecting both what individual academics find important, but also through the functioning of scientific 
governance systems. There may be ways that these scientific governance systems can be changed to give stronger and more positive signals of their research's value outside their immediately disciplinary confines.

Related to this, there is a clear policy implication in that the challenge of increasing the level of research utilization is not only a question of seeking to maximise the number of terminal knowledge transfers whilst seeking to avoid what Collini parodies as the 'medieval cookbook effect' (Collini 2011). It is also in ensuring that scientific governance systems give sufficient amplification to these external signals of the value of use to scientists, as that is associated with scientists making their research more usable, by increasing its cognateness with others (an antecedent to its eventual uptake). This means that research utilization and valorisation policy should not merely concern itself with stimulating licensing, patents and spin-offs, but in ensuring that user value signals are integrated more thoroughly into scientific governance processes more generally. There are many ways that this can be done to give positive feedback to scientists, for example in terms of supporting mechanisms for user peer review, and these need to be integrated into researchers' own value systems.

\section{Acknowledgements}

The authors acknowledge the EU-Spri Forum for the PhD Circulation grant provided to Julia Olmos Peñuela and to CHEPS as her host institution. The authors acknowledge the CSIC and other IMPACTO project researchers (INGENIO \& IESA) for their hard and very satisfactory work and the CSIC researchers whose questionnaire answers permitted developing the database. The authors would also like to thank Barend van der Meulen, the Rathenau Institute, the Netherlands, for a comment on a presentation that inspired this paper, as well as to Laurens Hessels for his correspondence on the issue of research dynamism.

\section{Notes}

1. One example of this public value failure is that in this view, the public value is maximised by academics privatizing as much of the knowledge as possible (to maximise economic income) this may well come at the expense of the use of that knowledge for wider societal gains (Slaughter and Leslie, 1997).

2. In this paper, 'researcher' and 'scientist' are used interchangeably to avoid excessive repetition, acknowledging that the literature uses these two phrases.

3. i.e. the transaction by which the knowledge is privatised and passed to a user (Zahra et al., 2007), such as licensing deals or spin-out company creation. Even protagonists admit that these kinds of transactions are at best a partial proxy for public returns which clearly opens the possibility for public value failure.

4. For a more elaborated version of this argument see Benneworth and Olmos-Peñuela (2014). 
5. Choosing 4 processes is at least partly an emergent choice because this corresponds with around $1 / 4$ of the sample; taking 3 processes would result in around $1 / 2$ of researchers counting as stars.

\section{Bibliography}

Adviesraad-voor-Wetenschaps (2007) 'Alfa en Gamma stralen.Valorisatiebeleid voor de Alfa- en Gammawetenschappen'. Rijswijk: Adviesraad voor Wetenschaps- en Technologiebeleid.

Balconi, M., Brusoni, S. and Orsenigo, L. (2010) 'In defence of the linear model: An essay', Research Policy, 39/1: 1-13.

Bate, J. (2011) The Public Value of the Humanities. London: Bloomsbury.

Bateman, T. S. and Hess, A. M. (2015) 'Different personal propensities among scientists relate to deeper vs. broader knowledge contributions', Proceedings of the National Academy of Sciences: 1-6, http://www.pnas.org/content/early/2015/02/23/1421286112.

Becher, T. and Trowler, P. R. (2001) Academic Tribes and Territories Intellectual Enquiry and the Culture of Disciplines. Buckingham: The Society for Research into Higher Education \& Open University Press.

Benneworth, P. (2015) 'Tracing how arts and humanities research translates, circulates and consolidates in society. How have scholars been reacting to diverse impact and public value agendas?', Arts and Humanities in Higher Education, 14/1: 45-60.

Berman, E. P. (2011) Creating the market university: How academic science became an economic engine. Princenton: Princeton University Press.

Boschma, R. (2005) 'Proximity and innovation: a critical assessment', Regional Studies, 39/1: 6174.

Bozeman, B. (2000) 'Technology transfer and public policy: a review of research and theory', Research Policy, 29/4: 627-55.

--- (2002) 'Public-value failure: When efficient markets may not do', Public Administration Review, 62 /2: 145-61.

--- (2012) 'Public Values Concepts and Criteria: The Case for "Progressive Opportunity" as a Criterion'. Paper prepared for Creating Public Values Conference, University of Minnesota, Center for Integrative Leadership, September 20-22, 2012 <http://www.leadership.umn.edu/documents/Bozeman6.4.12wtitlepage.pdf> accessed 23 March 2015.

Brewer, J. D. (2013) The Public Value of the Social Sciences: An Interpretive Essay. London: Bloomsbury.

Bush, V. (1945) 'Science, the endless frontier: A report to the President'. <http://www.nsf.gov/od/lpa/nsf50/vbush1945.htm.> accessed 12 September 2014.

Collini, S. (2011) What are universities for? London: Penguin.

CSIC (2012) 'Memoria anual del CSIC 2011'. Madrid: Consejo Superior de Investigaciones Científicas,

$<$ http://documenta.wi.csic.es/alfresco/downloadpublic/direct/workspace/SpacesStore /81d3f71c-819c-4787-9147-8c18b2d64fcb/CSIC_MEMORIA_2011_alta.pdf> accessed 17 September 2013.

D'Este, P. and Perkmann, M. (2011) 'Why do academics engage with industry? The entrepreneurial university and individual motivations', The Journal of Technology Transfer, 36 /3: 316-39.

D’Este, P., Llopis, O. and Yegros, A. (2013) 'Conducting pro-social research: Cognitive diversity, research excellence and awareness about the social impact of research': INGENIO (CSICUPV) Working Paper Series.

Dance, A. (2013) 'Impact: Pack a punch', Nature, 502/7471: 397-98. 
Delanty, G. (2002) 'The University and Modernity: A History of the Present'. In: Robins, K. and Webster, F. (eds.) The Virtual University: : Knowledge, Markets and Management, pp. 3148. Oxford: Oxford University Press.

Donovan, C. (2007) 'The qualitative future of research evaluation', Science and Public Policy, 34/8: 585-97.

Ernste, H. (2007) 'The international network university of the future and its local and regional impacts'. In: Harding, A., et al. (eds.) Bright satanic mills: universities, regional development and the knowledge economy, pp. 69-94. Aldershot: Ashgate.

Fromhold-Eisebith, M., Werker, C. and Vojnic, M. (2014) 'Tracing the social dimension in innovation networks'. In: Rutten, R., et al. (eds.) The Social Dynamics of Innovation Networks, pp. 221-39. London: Routledge.

Gertner, D., Roberts, J. and Charles, D. (2011) 'University-industry collaboration: a CoPs approach to KTPs', Journal of Knowledge Management, 15/4: 625-47.

Gibbons, M., et al. (1994) The new production of knowledge: the dynamics of science and research in contemporary societies. London: Sage

Gulbrandsen, M. (2012) 'But Peter's in it for the money'-the liminality of entrepreneurial scientists'. TIK WORKING PAPERS on Innovation Studies, No. 20120323 <http://www.sv.uio.no/tik/InnoWP/Gulbrandsen\%2020120323.pdf> accessed 20 March 2015.

Gulbrandsen, M. and Smeby, J.-C. (2005) 'Industry funding and university professors' research performance', Research Policy, 34/6: 932-50.

Hessels, L. K. and Van Lente, H. (2008) 'Re-thinking new knowledge production: A literature review and a research agenda', Research Policy, 37/4: 740-60.

Lam, A. (2011) 'What motivates academic scientists to engage in research commercialization:'Gold','ribbon'or 'puzzle'?', Research Policy, 40/10: 1354-68.

Latour, B. and Woolgar, S. (1979) Laboratory life: The social construction of scientific facts. London: Sage.

Lowe, R. A. and Gonzalez-Brambila, C. (2007) 'Faculty entrepreneurs and research productivity', The Journal of Technology Transfer, 32/3: 173-94.

Nowotny, H., Scott, P. and Gibbons, M. (2001) Re-thinking science: knowledge and the public in an age of uncertainty. Argentina: SciELO.

O'Shea, R. P., et al. (2005) 'Entrepreneurial orientation, technology transfer and spinoff performance of US universities', Research Policy, 34/7: 994-1009.

Olmos-Peñuela, J., Benneworth, P. and Castro-Martínez, E. (2014a) 'Are 'STEM from Mars and SSH from Venus'?: Challenging disciplinary stereotypes of research's social value', Science and Public Policy, 41/3: 384-400.

--- (2014b) 'Explaining researchers' readiness to incorporate external stimuli in their research agendas'. $\quad$ CSIC-INGENIO Working Paper № 2014-08 <http://www.ingenio.upv.es/sites/default/files/working-paper/2014-08.pdf> accessed 28 October 2014.

--- (2015) 'Are sciences essential and humanities elective? Disentangling competing claims for humanities' research public value', Arts and Humanities in Higher Education, 14/1: 61-78.

Rhoten, D. and Pfirman, S. (2007) 'Women in interdisciplinary science: Exploring preferences and consequences', Research Policy, 36/1: 56-75.

Roach, M. and Sauermann, H. (2010) 'A taste for science? PhD scientists' academic orientation and self-selection into research careers in industry', Research Policy, 39/3: 422-34.

Rüegg, W. (1992) 'Themes'. In: Ridder-Symoens, H.d. (ed.), A history of the University in Europe, pp. 3-34. Cambridge, UK: Cambridge University Press.

Salter, A. J. and Martin, B. R. (2001) 'The economic benefits of publicly funded basic research: a critical review', Research Policy, 30/3: 509-32.

Slaughter, S. and Leslie, L. L. (1997) Academic Capitalism: Politics, Policies, and the Entrepreneurial University. Baltimore: The Johns Hopkins University Press.

Small, H. (2013) The value of the humanities. Oxford: Oxford University Press. 
Spaapen, J. and van Drooge, L. (2011) 'Introducing 'productive interactions' in social impact assessment', Research Evaluation, 20/3: 211-18.

Stephan, P. E. and Levin, S. G. (1993) 'Age and the Nobel Prize revisited', Scientometrics, 28/3: 387-99.

Van Looy, B., et al. (2004) 'Combining entrepreneurial and scientific performance in academia: towards a compounded and reciprocal Matthew-effect?', Research Policy, 33/3: 425-41.

Van Rijnsoever, F. J. and Hessels, L. K. (2011) 'Factors associated with disciplinary and interdisciplinary research collaboration', Research Policy, 40/3: 463-72.

Van Rijnsoever, F. J., Hessels, L. K. and Vandeberg, R. L. (2008) 'A resource-based view on the interactions of university researchers', Research policy, 37/8: 1255-66.

Weingart, P. (2009) 'Editorial for Issue 47/3', Minerva, 47/3: 237-39.

Zahra, S. A., Van de Velde, E. and Larraneta, B. (2007) 'Knowledge conversion capability and the performance of corporate and university spin-offs', Industrial and Corporate Change, 16/4: 569-608.

Zucker, L. G. and Darby, M. R. (1996) 'Star scientists and institutional transformation: Patterns of invention and innovation in the formation of the biotechnology industry', Proceedings of the National Academy of Sciences, 93/23: 12709-16. 
The Center for Higher Education Policy Studies (CHEPS) is a research institute (WHW, Article 9.20) located in the Faculty of Behavioural and Management Scienes within the University of Twente, a public university established by the Dutch government in 1961 . CHEPS is a specialized higher education policy centre that combines basic and applied research with education, training and consultancy activities.

http://www.utwente.nl/bms/cheps/

$|c| h|l| p|s|$

Center for

Higher Education

Policy Studies 